\title{
Learning from the past to inform the future - A survey of consultant nurses in emergency care
}

\author{
Sarah Charters RGN, BSc (Hons) (Nurse Registrar) *, Suzanne Knight RGN, \\ BN (Hons), RN (Child) (Nurse Registrar), Jane Currie RGN, BSc (Hons) \\ (Honorary Nurse Registrar), Marie Davies-Gray RGN, BSc (Hons) (Nurse \\ Registrar), Mark Ainsworth-Smith RGN, BSc (Hons) (Nurse Registrar), \\ Stuart Smith RN, BSc (Hons), Dip HE (Nurse Registrar), Robert Crouch RN, \\ PhD, FRCN, FFEN (Consultant Nurse/Senior Lecturer)
}

Emergency Department, Southampton General Hospital, Tremona Road, Southampton, Hampshire SO16 6YD, UK

Received 4 May 2005; accepted 18 May 2005

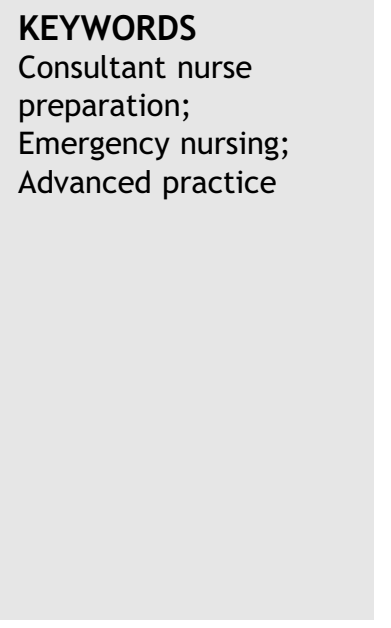

\begin{abstract}
Summary This paper reports the findings of a survey of UK consultant nurses in emergency care. The purpose of the survey was to elicit information regarding level of preparation for the consultant nurse role, the use of formal competency frameworks, current clinical scope of practice and perspectives on future preparation for the role. A semi-structured questionnaire was emailed to consultant nurses in emergency care. Respondents had an average of only 2 years in post and for $24 \%$ of respondents this was their second post as a consultant nurse. The survey identified that three quarters of the respondents had no specific preparation for the consultant nurse role. The remainder had varying levels of preparation ranging from brief induction to 6-month clinical training. It could be argued that this diversity of preparation is a reflection of the lack of clarity regarding the consultant nurse role and the ill-defined organisational frameworks within which some consultant nurse posts were established. With the exception of the expert practice domain and clinical leadership, the majority of respondents felt under prepared for one or more elements of the consultant nurse role. Clinically their scope of practice ranged from managing patients with minor illness or injury, to leading resuscitation teams. There was great
\end{abstract}

\footnotetext{
Corresponding author.

E-mail address: sarah.charters@suht.swest.nhs.uk (S. Charters).
} 
inequity in the level of preparation for the role, particularly in the transformational leadership, education and training, and practice and service development domains. Strategies for addressing these deficiencies are identified.

(c) 2005 Elsevier Ltd. All rights reserved.

\section{Introduction}

In early 2004, five senior emergency nurses were recruited to a dedicated consultant nurse education and development programme (Crouch et al., 2003). The 3-year programme is funded by a collaboration of three NHS Trusts: Southampton University Hospitals NHS Trust, Winchester and Eastleigh Healthcare NHS Trust, Southampton City Primary Care Trust; and the Hampshire and Isle of Wight Workforce Development Confederation. The pilot programme offers a unique opportunity for the five trainees, nurse registrars, to develop knowledge and skills in all four domains of the consultant nurse role and will enable both them and the programme leaders to inform the future development of consultant practitioner training and education. To facilitate the development of the Southampton pilot, a survey was conducted of Consultant Nurses in Emergency Care.

\section{Background}

In 1998, the Government announced the introduction of consultant nurses. The aim was threefold, to extend the career ladder for clinical nurses, to enhance professional leadership and to improve the quality of patient care (Walters, 2000). Consultant nurse posts were defined in terms of four principle role functions:

- Expert practice.

- Professional leadership and consultancy.

- Education, training and development.

- Practice and service development, research and evaluation (Health Service Circular, 1999).

The consultant nurse role requires considerable expertise and experience, for many it is the pinnacle of a career in nursing (Redfern, 2003). However, early findings of a Department of Health commissioned evaluation suggest that many experience role ambiguity, role conflict, overload and confusion regarding role boundaries (Guest et al., 2001). There is a high turnover in consultant nurse posts, which may be a reflection of poor organisational preparedness (Crouch et al., 2003). A num- ber of posts in emergency care remain unfilled. This is multifactorial, but one important element may be the lack of practitioner preparation for the role.

\section{Method}

A questionnaire was designed to elicit information regarding level of preparation for the role, the use of formal competency frameworks, current clinical scope of practice and perspectives on future preparation for the role. It was circulated by email to consultant nurses in emergency care. A mixture of dichotomous and open ended questions were used, with the simple demographic questions arranged first followed by open ended questions, allowing the respondent a warm up period (Polgar and Thomas, 2000).

\section{Sampling}

A combined approach of purposive and network sampling was employed. Purposive sampling allows the researcher to choose specific participants, who fulfil the interest of the research (Silverman, 2001). The Department of Health emergency care consultant nurse email list was used following a discussion with emergency consultant nurses at a network meeting. However, the initial mail out of this list revealed that it contained a number of individuals who were not consultant nurses in emergency care. These were discounted from the sample. A network sampling technique was employed to assist in identifying other emergency consultant nurses (Burns and Grove, 2001).

\section{Questionnaire}

The questionnaire was designed by the nurse registrars and piloted on two emergency consultant nurses working in the local region. From this, minor alterations were made to facilitate ease of use. The questionnaire was then emailed to partici- 
pants. After 2 weeks non-respondents were sent a reminder email along with a repeat copy of the questionnaire. The data was subjected to simple descriptive statistical analysis and thematic analysis of descriptive data (Morse and Field, 1996).

\section{Results}

In total, 44 consultant nurses were approached, 25 responded giving an overall response rate of $58 \%$. The data from respondents identified that the mean time since qualification was 18 years. On average, respondents had 14 years of emergency nursing experience. The average length of time in post as a consultant nurse was 2 years. $56 \%$ $(n=14)$ were appointed as an internal candidate. Of the respondents, $24 \%(n=6)$ were working in their second consultant nurse post. The type of registration and academic qualifications of the respondents are shown in Tables 1 and 2. On appointment to their first consultant nurse post, the highest academic qualification held by respondents was: $4 \%(n=1)$ diploma; $16 \%(n=4)$ bachelors degree; $72 \%(n=18)$ masters degree; $4 \%(n=1)$ PhD; 4\% $(n=1)$ did not answer. The consultant nurses were asked to approximate how they balanced their time with regard to the four domains of consultant practice. On average, they spent $50 \%$ of their time clinically, $20 \%$ in educational activities, 20\% in leadership activities (although some emphasized that they utilized their leadership skills $100 \%$ of their time) and $10 \%$ in research activities.

\section{Preparation for the consultant nurse role}

Respondents were asked about the specific preparation they received prior to their first consultant nurse appointment. Seventy two percent $(n=18)$ of respondents received no specific structured preparation prior to their appointment. Eighty percent $(n=20)$ identified at least one aspect of their

Table 1 NMC and paramedic registration status

\begin{tabular}{lc}
\hline NMC and paramedic registration & $\begin{array}{c}\text { Number of } \\
\text { respondents }\end{array}$ \\
\hline Adult & $24(96 \%)$ \\
Paediatric & $4(16 \%)$ \\
Mental health & $1(4 \%)$ \\
State registered paramedic & $1(4 \%)$ \\
Not answered & $1(4 \%)$ \\
\hline
\end{tabular}

role for which they felt under-prepared, from which emerged five common themes:

- Preparation for role within the organisation.

- Advanced clinical skill.

- Strategic role and consultancy.

- Research and publication.

- Transformational leadership.

The respondents were then asked how they thought consultant nurses should be prepared for the role. The areas identified were congruent with four of the above five themes and are therefore reported under the following headings.

\section{Role within the organisation}

Twenty percent $(n=5)$ of respondents identified difficulties relating to this area. These included: a lack of clarity with their role, a sense of isolation, and disparity regarding the organisation's expectations of their role. One described how " 4 years in, there is just beginning to be some clarity around the role", and another highlighted the difficulty of "working within an ill-defined organisational framework" asking "where do nurse consultants fit in?"

Recommendations regarding how consultant nurses may achieve a clear definition of role were given. Two respondents emphasised the need for a broad preparation for aspiring consultant nurses that includes all four aspects of the consultant nurse role. Other suggestions included shadowing consultant nurses and other health professionals, including medical consultants and consultants from professions allied to medicine; coaching, supervision and mentorship from existing consultant nurses; seeking clarity regarding the consultant nurse role; being given the opportunity to develop key knowledge and skills to meet a defined role; the development of a negotiated job plan, clear development plan; and development of a competency framework.

\section{Advanced clinical skills}

Only $8 \%(n=2)$ identified that they felt under-prepared for the clinical aspects of their role, one of whom identified that it would have been helpful to receive Emergency Nurse Practitioner (ENP) training prior to the commencement of their post. One respondent gave a very clear view of how aspiring consultant nurses should be prepared: "I feel very strongly that prospective nurse consultants would benefit from undergoing a predetermined clinical and educational programme at Masters level or above. This should be nationally agreed to prevent disparate programmes from 
Table 2 Academic qualifications of consultant nurses

\begin{tabular}{lc}
\hline Academic qualifications & Number of respondents \\
\hline PhD/clinical doctorate & $1(4 \%)$ \\
Masters degree & $4(16 \%)$ Currently studying \\
& $19(76 \%)$ \\
Bachelors degree & $4(16 \%)$ Currently studying \\
Diploma & $15(60 \%)$ \\
Post graduate cert/diploma in higher education & $1(4 \%)$ \\
Extended nurse prescribing & $4(16 \%)$ \\
& $2(8 \%)$ \\
Not answered & $2(8 \%)$ Currently studying \\
\hline
\end{tabular}

being developed that are designed with only local needs being addressed. The content of the course should mirror the scope and responsibilities of the role, with the main bulk being related to clinical practice. I personally feel that this should be a NMC registered qualification'.

Other recommendations for the preparation of aspiring consultant nurses included: development of advanced and expert clinical practice; gaining prescribing rights; development of X-ray request and interpretation skills; clinical shadowing with specific medical clinicians; and developing a clear idea of clinical direction (generalist $v$ specialist).

\section{Strategic role and consultancy}

Thirty two percent $(n=8)$ felt under-prepared for this aspect of the consultant nurse role. Problem areas identified included: cross-organisational working, strategic knowledge, corporate decisionmaking, induction and introduction at Trust senior management level, and the consultancy role outside of their department. One respondent stated: "working at an increasingly strategic level and developing links within the PCT has also been challenging'. Suggestions to address this included: shadowing the Director of Nursing Services, senior Trust management, members of the Strategic Health Authority and Workforce Development Confederation. Other suggestions included: developing political leadership skills and gaining access to health care politicians; gaining experience of, and exposure to, strategic planning and corporate development.

\section{Research and publication}

With regard to preparedness for role, a significant number of respondents, $36 \%(n=9)$, felt under-prepared for the research aspect, with one also identifying a lack of publication experience. Ideas to enhance the above included participating in research studies and developing a publication history.
The need for protected time for research and associated publications was highlighted, along with an identified need for an increase in administrative support. Twenty eight percent $(n=7)$ of respondents emphasised the need for pursuing an academic route and several emphasised the need for preparation at Masters level. Other suggestions included the shadowing of academics and educators.

\section{Transformational leadership}

Twenty percent $(n=5)$ identified lack of transformational leadership skills such as negotiation and influencing, time management, project management, and accessing funding for projects. Recommendations for preparation for transformational leadership included: decision making and assertiveness skills, change management skills and experience of senior management roles. One respondent stated "I would have found it beneficial to have had a nurse consultant training programme that covered things like leading policy development, negotiating and influencing skills and applying for funding."

\section{Competency frameworks}

The consultant nurses were asked if they used a competency framework and, if so, they were asked to give brief details of the framework. Eighty percent $(n=20)$ stated they did not use a competency framework, 8\% used the Faculty of Emergency Nursing competencies (Endacott et al., 1999) or Skills for Health (Skills for Business, 2004). Others were devising their own learning outcomes in the light of the Knowledge and Skills Framework linked to Agenda for Change (Department of Health, DOH, 2004).

\section{Ways of working}

Respondents were asked to describe their clinical practice in each area of emergency care and were 
Table 3 Consultant nurse areas of independent practice

\begin{tabular}{lc}
\hline Area of department & Independent practice \\
\hline Minor injury/illness & $20(80 \%)$ \\
Majors & $4(16 \%)$ \\
All patients & $12(48 \%)$ \\
Limited presentations & \\
Paediatrics & $4(16 \%)$ \\
All patients & $13(52 \%)$ \\
Limited presentations & \\
Resuscitation & $1(4 \%)$ \\
All patients & $5(20 \%)$ \\
Limited presentations &
\end{tabular}

asked to specify where they undertook an autonomous role, in terms of independent decision-making. Table 3 demonstrates the areas and degrees of independent practice.

\section{Professional support}

The consultant nurses were asked to identify the types of professional support that they accessed. These are summarised in Table 4.

The survey identified that $88 \%(n=22)$ of consultant nurses felt supported by their department and $76 \%(n=19)$ by their Trust. One respondent felt unsupported by their Trust and one felt unsupported by both their department and Trust. Of the positive comments received, $36 \%(n=9)$ highlighted that they had easy access to their Trust Chief Executive or Director of Nursing and 44\% $(n=11)$ reported good working relationships with key players within their department and Trust, including senior medical staff. One respondent reported that: "I gain support from my senior nursing and medical peers who are committed to the consultant nurse role"'. The remaining $12 \%(n=3)$ reported variable degrees of support, for example: "I only feel supported because I requested it at

Table 4 Types of professional support accessed

\begin{tabular}{lc}
\hline Type of professional support & $\begin{array}{c}\text { Number of } \\
\text { respondents }\end{array}$ \\
\hline Clinical supervision & $11(44 \%)$ \\
Coaching & $4(16 \%)$ \\
Mentorship & $10(40 \%)$ \\
Professional supervision & $5(20 \%)$ \\
No formal professional support & $2(8 \%)$ \\
Not answered & $2(8 \%)$ \\
\hline
\end{tabular}

both department and Trust level" One respondent outlined difficulties with interactions with nursing colleagues: "nurses can have difficulties relating to a role that carries no management responsibilities'. Twenty eight percent $(n=7)$ identified ambiguity regarding their role or position within their Trust, highlighting a mismatch between their influence and authority, which led them to feel unsupported.

\section{Satisfaction with role}

When asked if there was anything about their current role that they would like to change, some respondents expressed concern regarding the clarity of their role and not having clear lines of authority and responsibility. Another issue was the unrealistic expectations of others; one described: "there is a heavy burden of being all things to all people". Sixteen percent $(N=4)$ mentioned the pressure of "other work" pulling them away from their clinical time, some reporting an expectation that they would drop clinical commitments for meetings.

\section{Major achievements}

Demonstrating outcomes has been highlighted as an important area for consultant nurses; respondents were asked to describe what they perceived to be their main achievements. These are shown in Table 5.

\section{Study limitations}

A significant limitation of the study was the difficulty in obtaining an exhaustive list of current emergency consultant nurses from the Department of Health, which may have resulted in a less comprehensive and representative sample. A further limitation was the $58 \%$ response rate, which may have introduced non-response bias to the study results because it is possible that the characteristics and responses of non-responders would be different to those who did respond (Polit et al., 2001). Given the inaccuracies of the Department of Health list of consultant nurses, it is possible that some of the non-responders were not consultant nurses or engaged in emergency care. The self-administered nature of the questionnaire may have reduced the depth and clarity of the information obtained and limited the opportunity to expand on key points. There was also a potential for response bias given 
Table 5 Main achievements in role, as perceived by respondents

\begin{tabular}{lc}
\hline Main achievements & Number of respondents \\
\hline Supporting the development of the nursing team & $14(56 \%)$ \\
Staff training & $8(32 \%)$ \\
Establishment of nurse led minor injuries service & $7(28 \%)$ \\
Development of other clinical services & $4(16 \%)$ \\
Clinical guideline and protocol development & $6(24 \%)$ \\
Strategic and change management project & $10(40 \%)$ \\
Audit & $5(20 \%)$ \\
Governance and quality strategies & $5(20 \%)$ \\
Raising profile of nursing & $5(20 \%)$ \\
Development of own clinical expertise and autonomous practice & $6(24 \%)$ \\
Academic and research activity (includes supporting others) & $6(24 \%)$ \\
Multi-agency working & $4(16 \%)$ \\
\hline
\end{tabular}

the email infringement on anonymity. However, in the covering email respondents were informed that any trace of identity would be removed prior to data analysis.

\section{Discussion}

Three quarters of the respondents had no specific preparation for the role of consultant nurse. The remainder had varying levels of preparation ranging from a brief induction to six months clinical training. Respondents identified that formal preparation should mirror the four domains of the consultancy role, with the main emphasis on clinical skills. In terms of standardising the role, respondents identified the potential benefit of a national preparation programme, at Masters level. The qualification could be accredited with the Nursing and Midwifery Council in the light of establishing regulation for 'higher level' practice (NMC, 2005).

Respondents had worked for an average of two years as a consultant nurse but, for $24 \%$ of respondents, this was their second post. It could be argued that the high turnover of consultant nurses in a number of posts reflects a lack of clarity regarding the consultant nurse role and the illdefined organisational frameworks within which some consultant nurse posts were established. Some respondents cited the lack of role clarity within their organisation and a lack of support as their primary reason for leaving their first consultant nurse post and others reported ongoing difficulties identifying their role and level of authority within their current post. These problems may be a reflection of either the individual's, or the organisation's, lack of preparation for the consultant nurse post and may also indicate a lack of under- standing of their role from work colleagues and line managers.

The majority of respondents $(84 \%)$ received some form of professional support, in the form of clinical supervision, mentorship, coaching or professional supervision. This was provided by a range of facilitators, including other consultant nurses, emergency medicine consultants, academics, directors of nursing services and external leadership coaches. Some received two or more forms of professional support from different facilitators. Interestingly, two respondents who did not feel fully supported by their Trust did not receive any formal professional support from within their Trust. This highlights how important it is for those who employ consultant nurses to set up mechanisms for formal professional support.

\section{Expert practice}

In terms of expert practice, the majority of consultant nurses felt well prepared. Their scope of practice ranged from managing patients with minor injury and illness to managing major illness, major injury and resuscitation patients. The existent variety in the clinical role is testimony to the lack of standardisation of the consultant nurse role within emergency care. This reflects the diversity of the emergency care client group and may also be a reflection of either individual expertise within the speciality or the operational needs of specific departments. Two respondents highlighted that the consultant nurse role in other specialities was more clearly defined. By including core role functions into a national competency framework, such as the ability to assess, diagnose and treat patients with minor injury and illness or major injury and illness (depending on area of specialism), emergency 
consultant nurses may improve the clarity and unity of their role in the expert practice domain.

\section{Professional leadership and consultancy}

Most respondents felt prepared for their leadership role. Those who did not cited a lack of knowledge and skills in accessing funds, managing projects, and utilising negotiating and influencing skills. A lack of role clarity and unclear role boundaries may lead to difficulties for consultant nurses in establishing their level of authority and influence. Historically nurses have had little influence within health care and this culture has been slow to change. Nursing should endeavour to maintain its present momentum by ensuring those in senior positions possess the skills of influence, negotiation and leadership.

Shadowing the Director of Nursing Services, other senior members of the Trust, and members of the Strategic Health Authority was identified as a strategy to embed an individual into the consultant nurse role and familiarise them to their place within the organisation. To influence on a national level, working alongside political leaders was identified as advantageous to the role.

To be successful in influencing and initiating change, advanced clinical nurses must work in a culture that is open and supportive of new roles and change management (Whyte et al., 2000). The majority of respondents felt well supported by both their department and trust. A third specifically noted that they enjoyed an 'open door' policy from their Chief Executive and Director of Nursing, which helped to raise the profile of nursing developments and supported the implementation of new services. For those respondents who described a lack of support, this situation appeared to have a profound affect on their job satisfaction.

\section{Education, training and development}

The majority of consultant nurses reported that they hold a Masters degree qualification. Masters level training equips nurses with critical thinking, and higher-level decision making skills, which are essential in advanced practice (Currie, 2004; Castledine, 2003; Gerrish et al., 2003). A significant number of consultant nurses were actively involved in the education and development of their nursing colleagues and this was commonly linked to the development of new services and quality initiatives. This demonstrates the tangible way in which consultant nurses are exerting influence over the delivery of patient care.

Some respondents suggested the formulation of an education and development programme, which is designed to prepare future consultant nurses for all four aspects of the consultant nurse role. However, few suggestions were given by the survey respondents regarding how aspiring consultant nurses should specifically prepare for the education, training and development aspect of the role. The opportunity to shadow academics and educators was suggested, but future consultant nurses should also consider what role they would undertake within the formulation and delivery of education and training programmes and ensure that they are prepared for this. Preparation may include formal postgraduate teaching qualifications.

The majority of respondents did not use a competency framework, although the Knowledge and Skills Framework within Agenda for Change ( $\mathrm{DOH}$, 2004) was identified by some respondents as a prompt to devising professional learning outcomes. This reflects the general lack of formalised competency frameworks and difficulty in clarifying the consultant nurse role. There is work underway to adapt the Faculty of Emergency Nursing competency framework for consultant nurses.

\section{Practice, service development, research and evaluation}

Despite the fact that the majority of consultant nurses hold a masters degree, one-third felt unprepared for the research aspect of their role. Most of the consultant nurses described active engagement in practice and service developments, which indicates that they are involved in research utilisation. Several respondents also reported providing support to their colleagues in the development of research projects, conference presentations and publications, indicating that they are perceived as a source of expert advice in these activities. It is important that consultant nurses have protected time to participate in research and to produce publications. This may be facilitated, in part, by adequate administrative support. Stronger links with academic institutions may also support consultant nurses in the development of their research skills. The current trend towards the expectation that consultant nurses will hold a PhD or Clinical Doctorate should facilitate greater involvement in research activity.

\section{Conclusions}

With the exception of the expert practice domain and clinical leadership, the majority of respondents felt under prepared for one or more elements 
of the consultant nurse role. Clinically, the scope of practice ranges from the management of patients with minor illness or injury, to leading resuscitation teams. Currently there is great inequity of levels of preparation for the role, greatest in the transformational leadership, education and training, and practice and service development domains. Strategies for addressing this are recommended below.

\section{Recommendations}

Following the completion of this survey, the authors recommend the following outcomes:

- Introduction of a nationally standardised trainee emergency consultant nurse programme and curriculum, facilitating professional development in all four domains.

- Creation of a consultant nurse development framework and pathway, which is recognised by the NMC, allowing simple migration between trusts across the UK.

- Development of a nationally agreed emergency consultant nurse competency framework.

\section{Acknowledgements}

The authors acknowledge the support of Ruth Buckley and Alan Charters during the pilot phase of their study.

\section{References}

Burns, N., Grove, S., 2001. The Practice of Nursing Research Conduct, Critique and Utilization, fourth ed. WB Saunders, Philadelphia.

Castledine, G., 2003. The development of advanced nursing practice in the UK. In: McGee, P., Castledine, G. (Eds.),
Advanced Nursing Practice. Blackwell Publishing, Oxford, pp. $8-16$.

Crouch, R., Buckley, R., Fenton, K., 2003. Consultant nurses: the next generation. Emergency Nurse 11 (7), 15-17.

Currie, J., 2004. Master's degree - why bother?. British Journal of Nursing 13 (19) 4.

Department of Health, 2004. The Knowledge and Skills Framework (NHS KSF) and the Development Review Process. Department of Health, London.

Endacott, R., Edwards, B., Crouch, R., Castille, K., Dolan, B., Hamilton, C., Jones, G., MacPhee, D., Manley, K., Windle, J., 1999. Towards a faculty of emergency nursing. Emergency Nurse 7 (5), 10-16.

Gerrish, K., MacManus, M., Ashworth, P., 2003. Creating what sort of a professional? Master's level nursing is a professional strategy. Nurse Enquiry 10 (2), 103-112.

Guest, D., Pecci, R., Rosenthal, P., Montgomery, J., Redfern, S., Young, C., Wilson-Barnett, J., Dowe, P., Evans, A., Oakley, P., 2001. A preliminary evaluation of the establishment of Nurse, Midwife, and Health Visitor Consultants report to the Department of Health. Research Paper 007. King's College London, London (Online 14 Jan 2005). Available from: <http://www.kcl.ac.uk/nursing/nru/ nruresrep.html>.

Health Service Circular, 1999. HSC 1999/217 Nurse, Midwife and Health Visitor Consultants. National Health Service Executive, London.

Morse J., Field, P., 1996. Nursing Research: The Application of Qualitative Approaches

Nursing and Midwifery Council, 2005. Consultation on a Framework for the Standard for Post Registration Nursing. NMC, London.

Polgar, S., Thomas, S., 2000. Introduction to Research in the Health Sciences, fourth ed. Churchill Livingstone, Edinburgh.

Polit, D., Beck, C., Hungler, B., 2001. Essentials of Nursing Research Methods, Appraisal and Utilisation, fifth ed. Lippincott, Philadelphia.

Redfern, L., 2003. Clinical Pinnacle Nursing Standard 17 (22), 96.

Silverman, D., 2001. Interpreting Qualitative Data, second ed. Sage Publications, London.

Skills for Business, 2004. Skills for Health: Emergency Care Competencies (Online 22 March 2005). Available from: <http://www.skillsforhealth.org.uk>.

Walters, G., 2000. Managing new roles within the service. In: Hunphris, D., Masterson, A. (Eds.), Developing New Clinical Roles: A Guide for Health Professionals. Churchill Livingstone, London, pp. 97-121.

Whyte, D., Lugton, J., Fawcett, T., 2000. Fit for purpose: the relevance of master's preparation for professional practice of nursing. A 10 year follow-up study of postgraduate nursing courses in the University of Edinburgh. Journal of Advanced Nursing 32 (5), 1072-1080.

Available online at www.sciencedirect.com

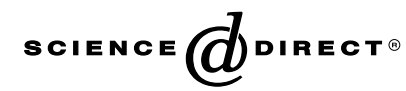

